\title{
Г.Г. Король
}

\section{РЕАЛИСТИЧНЫЕ ОБРАЗЫ-«ЛИЧИНЫ» В СРЕДНЕВЕКОВОЙ ЦЕНТРАЛЬНОЙ АЗИИ: ПОРТРЕТ ИЛИ СИМВОЛ}

\author{
Исследование выполнено при финансовой поддержке РФФИ (проект № 15-01-00306 (a)).
}

\begin{abstract}
Рассмотрены образы-«личины» на предметах торевтики малых форм рубежа I-II тыс. из регионов их концентрации в Центральной Азии: Саяно-Алтая и Тянь-Шаня. Выявлены особенности иконографии образов. Для Саяно-Алтая характерна «портретность» изображений, по которой можно предположительно судить об антропологических типах лиц. Для Тянь-Шаня отмечен процесс придания изображениям, имеющим аналогии из Саяно-Алтая, устрашающих деталей, превращающих «портретные» образы в звероподобные лики. На основе возможного смыслового содержания образов-«личин» сделан вывод об их символичности, связанной с мировоззрением средневековых кочевников.

Ключевые слова: Центральная Азия; Средневековье; торевтика малых форм; образы-«личины»; семантика.
\end{abstract}

На рубеже I-II тыс. в декоративно-прикладном искусстве кочевников Центральной Азии (в широком понимании термина) и их соседей, представленном торевтикой малых форм (преимущественно украшения снаряжения всадника и коня), интересны антропоморфные образы-«личины»: относительно реалистичные; условные, стилизованные, иногда териоантропоморфные. Изделия представлены подвесками в форме человеческих лиц, есть и изображения (иногда в сочетании с растительным орнаментом) на бляхах других форм. Универсальность мотива маски-личины, его существование на всем Западе со времен Античности и встречаемость с характерной всеобщностью в искусстве Азии всех эпох хорошо известны. Это подтверждают и многочисленные археологические находки. Для региона Центральной Азии наибольшая концентрация находок подобных предметов отмечена в Саяно-Алтае, а также в Чуйской долине Тянь-Шаня.

На обширной территории Саяно-Алтая в конце I тыс. н.э. проживали многочисленные племенные группы тюркской этнической общности, соседствовавшие с потомками более древнего аборигенного населения (угро-самодийские, тунгусо-манчжурские племена). Это был огромный этнически разнородный массив, который, по мнению специалистов, в антропологическом отношении был относительно однородным [1. С. 21]. Со временем возвышения Кыргызского каганата (с середины IX в.), усиления этнополитического объединения западных соседей кыргызов - кимаков совпадают становление и расцвет, широкое распространение на этой территории наиболее яркого образца евразийского стиля в искусстве - так называемого степного орнаментализма. В декоре торевтики малых форм преобладает растительный тип, незначительное число представлено зооморфными и антропоморфными изображениями. К последним относятся и «личины».

Одна из упомянутых выше группа личин - стилизованные, схематизированные личины, в том числе те- риоантропоморфные. Они разнообразны и наиболее многочисленны [2. Рис. 22]. Необходимо отметить, что средневековые жители Саяно-Алтая, особенно Минусинской котловины на Среднем Енисее, жили в окружении памятников древних эпох, среди них - каменные окуневские изваяния с антропоморфными личинами эпохи бронзы. Можно предположить, что появление в Средневековье миниатюрных личин другой иконографии на другом материале [3], передающих образ индуистской, буддийской и тибетской мифологии - Киртимукхи, имело благоприятную почву для адекватного восприятия. Средневековые новации были продолжением традиции почитания антропоморфных личин населением края.

Другая группа личин - антропоморфные образы, передающие портретные черты лица человека, характерны именно для Саяно-Алтая. Рассмотрим их подробнее. По разработанной ранее типологии они составляют группы 2-4 [2. Рис. 22]. Одна из них (рис. 1, 1-10, 24) представлена подвесками (группа 3) с рельефными портретными изображениями человеческих лиц преимущественно со смешанными европеоидно-монголоидными чертами. Большинство имеют детально разработанные усы, бороду (иногда что-то одно); прическу или головной убор. Одна личина (рис. 1,8) - безусая и безбородая, с 8-образными выступами под ушами (серьги?). Другая (рис. 1, 10) - с усатым лицом, пухлыми губами с четко прорисованной выемкой верхней губы. Это сплошная тяжелая (свинцовая?) подвеска, возможно, служившая матрицей для отливки бронзовых накладок. Особый интерес представляет матрица (материал не ясен). Изображенному на ней лицу (рис. 1, 5), правда, очень «затертому» и сглаженному, по типу (европеоидное с выделенными скулами) и ряду иконографических деталей (вплоть до чуть неровной линии спинки носа) очень близки две практически идентичные подвески из разных регионов Саяно-Алтая: Минусинской котловины Среднего Енисея (рис. 1, 4, 24 - рисунок и фото одного предмета) и северных предгорий Алтая. 

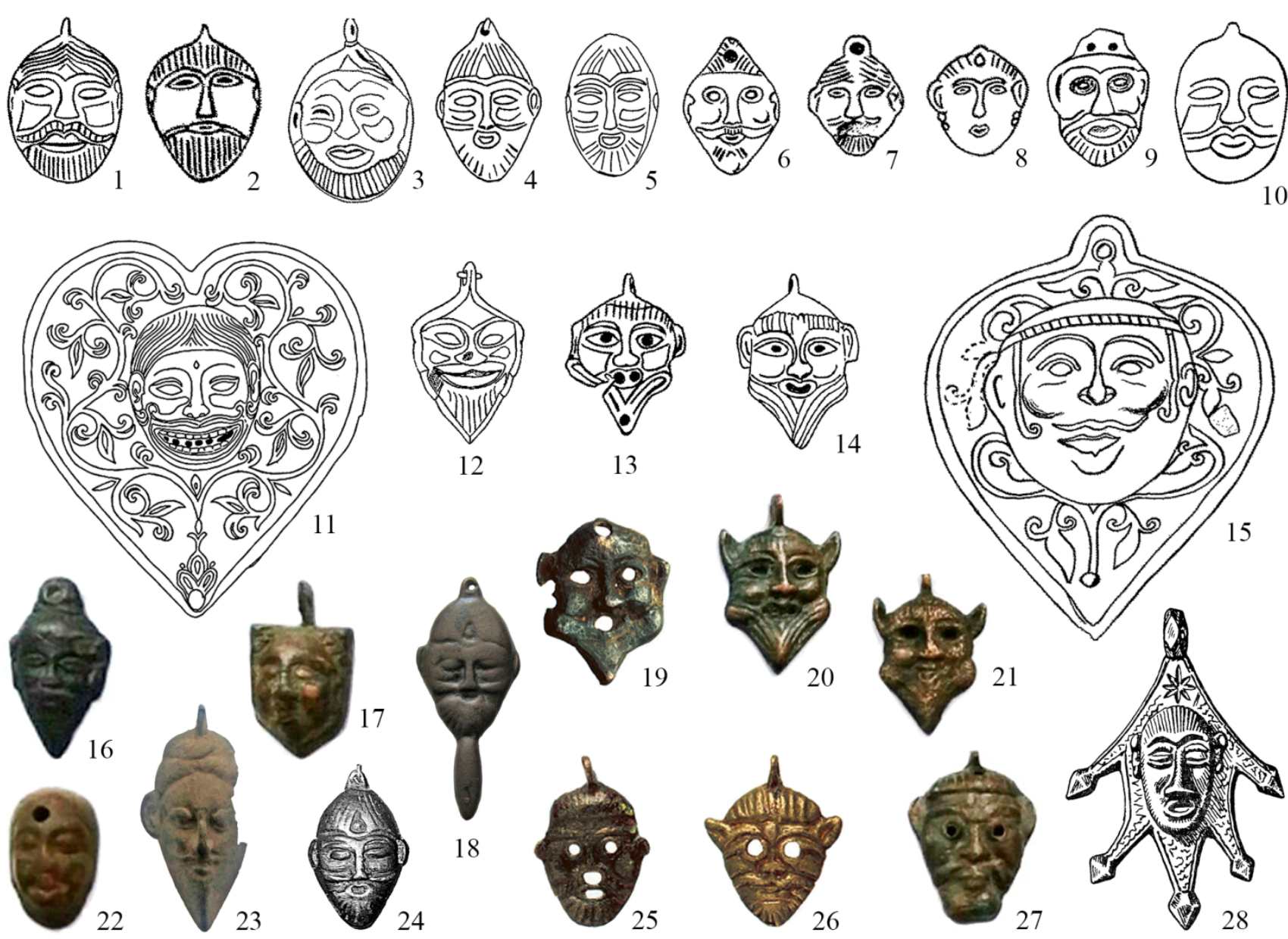

Рис. 1. Средневековые портретные личины из Саяно-Алтая (1-15, 24), Тянь-Шаня (16-23, 25-27) и этнографическая аналогия (28)

Это уникальные случаи находок матриц для отливки изделий на данной территории. В целом облик личин этой группы, в том числе тщательная разработка названных выше деталей, наиболее близок к личинам на сердцевидных бляхах (группа 2). Личины на этих бляхах с растительным декором рассматриваются как антропоморфные, условно портретные (см. рис. 1, 11, 15).

Личины группы 4 (см. рис. 1, 12-14) происходят из одного региона Саяно-Алтая - Минусинской котловины. Их можно охарактеризовать также как портретные, с деталями, близкими к изображениям предыдущей группы (борода, прическа). Но лица эти большеглазые, в одном случае - с подчеркнуто наклонно расположенными глазами, напоминающие портреты согдийцев, с выступающими округлыми щеками. У всех - характерные клинообразные бородки. Сравнительным материалом могут служить раннесредневековые согдийские терракоты, среди которых есть и так называемые местные персонажи, и изображения тюркского типа [4. С. 262, 297, 310]. Существует мнение, что в Средневековье был типологический шаблон (миндалевидные глаза, брови вразлет, нос с широкими крыльями), в соответствии с которым художники изображали воинов тюркского происхождения. В конце I тыс. н.э. усы и борода демонстрировали социальный статус мужчины.
Бритые лица были характерны для гуламов - профессиональных воинов тюркского происхождения в армиях мусульманского Востока [5. С. 134].

Исходя из особенностей личин и опираясь на палеоантропологический и современный материал [2. C. 108-112], можно предположить, что среди личин представлен преимущественно южносибирский тип (современные народы Алтая и Хакасии). Экземпляры с клиновидными бородками (см. рис. 1, 12-14) предположительно можно связать с памиро-ферганским антропологическим типом, характерным для ираноязычного и тюркоязычного населения Средней Азии. Несмотря на различия и возможное отнесение личин к разным антропологическим типам, у них много общего в стилистике изображения лиц. Основные типажи личин характерны для населения Саяно-Алтайского нагорья как современного, так, вероятно, и средневекового.

Из Чуйской долины Тянь-Шаня (преимущественно Краснореченского городища, основанного согдийцами) происходят подвески-личины и изображения личин на ременных украшениях [6. Рис. $33,34,37,133$; 7. Рис. 1] с хорошо читающимися портретными особенностями лиц (см. рис. 1, 16, 17, 19, 22. Фото: А.М. Камышев). Некоторые из них (в первую очередь широколицые с выделенными скулами, с клиновидными бородками) 
имеют сходство с подобными личинами из СаяноАлтая (см. рис. 1,19 , ср. с 13, 14; другой вид сходных личин см. рис. 1, 10, 22). Интерес представляет находка (рис. 1, 18 по: [8. Рис. 3, 7]) из отвалов «археологической зоны» средневекового города Баласагун (городище Бурана) в Чуйской долине, изначально согдийской колонии, а с середины Х в. - столицы созданного тюрками государства Караханидов. Данная подвеска посвоему уникальна, хотя и имеет чрезвычайно близкие аналогии с самим лицом (ср. с рис. 1, 4, 24). Она совмещает в себе детали двух саяно-алтайских групп, выделенных автором ранее: группы 3, о которой шла речь выше, и группы 6 [2. С. 104-106. Рис. 22, 25] - условных изображений лиц на подвесках, имеющих характерный длинный выступ-«бороду» (?), который можно видеть на каменных древнетюркских изваяниях и в раннесредневековой терракоте Средней Азии.

Помимо Саяно-Алтая личины с выступом«бородой» известны в лесостепном Причулымье, северной прилегающей к Саяно-Алтаю территории. Кроме того, находки бронзовых личин совершенно иной стилистики, чем саяно-алтайские (шире центральноазиатские), но также с выступом-«бородой», нередки в средневековых памятниках Омского Прииртышья [9. Рис. 239, 242], зафиксированы в этнографических комплексах и случайных сборах на севере Западной Сибири [10. Рис. 145, 150]. Отметим, что среди последних имеется пряжка с изображением личины местного облика [Там же. Рис. 327]. Сам принцип использования поверхности подобного предмета идентичен практике раннесредневековых тюрков [2. С. 258, 326. Рис. 22, 26].

Возвращаясь к личинам с портретными чертами, происходящими из Тянь-Шаня, отметим не имеющую аналогий случайную находку из района оз. Иссык-Куль - подвеску, на которой видим узкое лицо без выделенных скул, крупные, чуть миндалевидные глаза, усы и узкую клиновидную бороду, видимо, чалму на голове (см. рис. 1, 23. Фото: А.М. Камышев). (Показательно, что нашедший подвеску местный житель не может пока с ней расстаться и передать в музей, так как знакомые и родственники утверждают, что лицо на подвеске - его портрет.) Для нас это интересно также с точки зрения точности передачи черт лица средневековым мастером. Антропологический тип жителя современной Киргизии определенно можно соотнести со средневековым.

Особенностью собрания подвесок-личин из Чуйской долины (преимущественно с Краснореченского городища и его округи) можно считать наличие личин монстров со звериными заостренными ушками, созданных не только по образцам портретных личин, но иногда просто идентичных им. Такие экземпляры совершенно не известны по материалам Саяно-Алтая и прилегающих территорий. К примеру, интересно сравнить саяноалтайские подвески-личины (см. рис. 1, 12-14) и краснореченские (см. рис. 1, 19-21), некоторые из них, казалось бы, сделаны по одним образцам. Первые изготовлены на более высоком уровне мастерства, а вторые не только худшего качества, но и имеют детали, свидетельствующие и о другой смысловой основе этих изображений (см. рис. 1, 20, 21). Эти детали - не только звериные ушки, мало сочетающиеся с портретной личиной, но намеренное придание лицам устрашающего вида: большие отверстия на месте глаз, рта, иногда носа. Можно даже проследить, как подвергались изменению портретные личины: экземпляры без звериных ушек, но с намеренно проделанными отверстиями (см. рис. 1, 19, 25, 27); экземпляры с ушками и без нарочито круглых крупных отверстий на месте глаз, рта (см. рис. 1, 20, 21); экземпляры со всеми перечисленными особенностями (см. рис. 1, 26). Таким образом, можно констатировать, что типологически сходные с портретными некоторые личины из Чуйской долины имеют черты, не позволяющие видеть в них портретные изображения.

Возникает вопрос о смысловой основе подобных образов. Коллектив авторов [7] в работе, посвященной тенгрианству как мировоззрению (вере) и форме жизненного существования тюрко-монгольских кочевников евразийских степей, рассматривает много его аспектов. В специальном разделе об основных принципах тенгрианства (мировоззрение, экология, гармония с природой) внимание уделено погребально-поминальной традиции, связанной с поклонением духам предков. В качестве образца художественного (материального) воплощения подобных представлений приводятся некоторые из рассмотренных выше личин [Там же. Рис. 1]. Они соотнесены не только с духами предков, но и с духами-покровителями элементов природы: гор, рек, деревьев, земли.

Почему помимо портретных образов наблюдается придание устрашающего вида и звероподобности личинам, которые в оригинале были определенно «портретами», остается неясным. Можно размышлять на эту тему, учитывая особенности формирования средневековых городов на этой территории, потоки переселенцев из Согда в раннем Средневековье, симбиоз с кочевым населением, совместное проживание представителей разных религий, а также формирование со второй половины X в. государства Караханидов, первой тюркской династии, принявшей ислам. На данном этапе можно лишь констатировать, что по тем или иным причинам «портретные» личины, имевшие некий свой смысл, стали носителями другой смысловой основы. Они стали символами другого порядка.

Возвращаясь к портретным личинам Саяно-Алтая, отметим упомянутые выше личины в обрамлении растительного декора на крупных сердцевидных бляхах (см. рис. $1,11,15)$. Помимо явно устрашающего оскала на одном варианте собирательного портрета имеется и другой вариант - абсолютно миролюбивое лицо с характерными антропологическими и этническими (?) особенностями.

На этих предметах личины усилены растительными декоративными элементами. Это подчеркивает глубинный смысл назначения рассматриваемых декорирован- 
ных предметов, деталей ременной гарнитуры коня и всадника, - придавать их носителю (всаднику с конем) помимо защиты дополнительную жизненную энергию. Наделение подобных украшений охранительными, придающими силу и стойкость, а также благопожелательными функциями представляется их главным смысловым содержанием. Здесь следует вспомнить понятие qut (kym), связанное в культурных традициях народов тюркоязычного мира и его соседей, а также в древнетюркском языке с понятиями «дух, душа, жизненная сила, благо, благодать, достоинство, величие и т.д.» [11. С. 109, 110]. Е.А. Алексеенко в работе об этнокультурных аспектах шаманства у кетов [12. Рис. 4], рассматривая кетское куm, в качестве иллюстрации приводит редкий культовый предмет - бронзовую подвеску с личиной в центре (см. рис. 1, 28). Заметим, что личина при некоторой условности тоже «портретная»: с особенностями типа лица, прически, в ушах - воз- можно, серьги (ср. с рис. 1, 8). Но это скорее обобщенный образ-символ.

С этим же смысловым аспектом, а также династическим и, возможно, религиозным можно связывать уникальные наборы с «портретами» (рис. 2, 1) на деталях поясных наборов из памятников конца I - начала II тыс.: Хойцегорского могильника в Южном Забайкалье и могильника Октябрьский в Кузнецкой котловине Саяно-Алтая. Возможно, религиозный смысл композиций: фигуры с характерными головными уборами, иногда в коронах, со сложенными у груди руками, сопровождающие главный персонаж, подчеркивал верховенство его власти, данной небесами. Такая интерпретация, созвучная мировоззренческим основам тенгрианства, была бы вполне понятна тюркскому воину, хотя и выполнена композиция в традициях инородной мифологической или религиозной основы другой культуры [13].
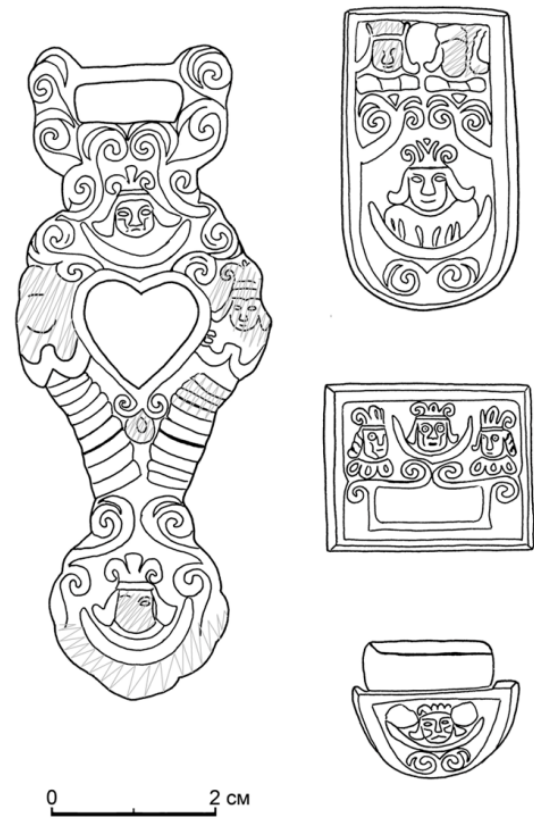

1
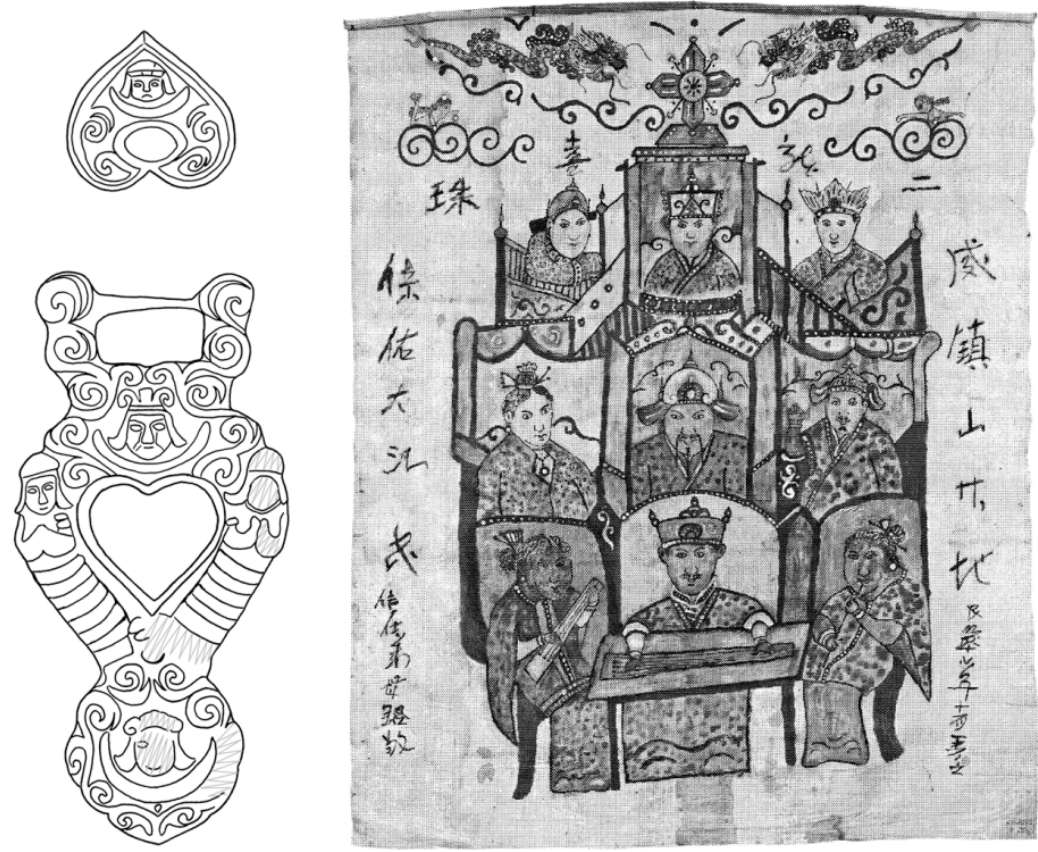

2

Рис. 2. «Хойцегорский портрет» Х в. из Южного Забайкалья (1) и «саола» (вместилище родовых духов) нанайского шамана М.Т. Оника, 1970-е гг. (2)

В качестве сходного алгоритма заимствований инородных средств выражения собственных воззрений, который представляется универсальным, приведем этнографический материал с Нижнего Амура [14, 15]. Среди предметов традиционного культа нанайцев в рамках шаманизма есть шаманские «иконы» (мио) - нарисованные на бумаге или ткани изображения богов-покровителей нанайских родов. Внешне это подражание китайским бумажным иконам (мё), которые привозили из Маньчжурии. Но в исполнении шамана и одновременно хорошего художника они приобретали особый смысл, представляя родовых богов (см. рис. 2, 2 по: [15. Рис. 9]).

Заметим некоторое сходство размещения персонажей рядами в несколько ярусов с композицией на хой- цегорских украшениях. Одиночные изображения на них, возможно, как-то входили в общую семантику всего «сюжета» поясного набора, составленного из отдельных бляшек. В данном случае набор известных нам типов изображений слишком ограничен, чтобы судить более обоснованно о смысле общего «сюжета». Его размещение на, видимо, парадном, судя по качеству и нарядности украшений (хойцегорские изготовлены из «золотой» латуни), поясе, которым воин мог быть награжден, также подчеркивает иерархию власти любого уровня (не обязательно высшего) и саму идею власти как данность свыше.

Итак, реалистичные образы-«личины» в средневековой Центральной Азии, представленные на предме- 
тах торевтики малых форм рубежа I-II тыс., сконцентрированы в регионах Саяно-Алтая и Чуйской долины Тянь-Шаня. В Саяно-Алтае преобладают предметы с настолько реалистичными изображениями, что по ним даже можно судить об антропологических типах средневековых жителей региона и сопредельных территорий (с пониманием того, что сопоставление условно). В Чуйской долине Тянь-Шаня представлены предметы, отражающие специфический процесс преображения «портретов» в звероподобные личины. Причины такой метаморфозы требуют специального изучения.

Даже определенно портретные изображения, скорее всего, были не просто портретами реальных персон, а собирательными образами, символами. Популярность подобных предметов, как и других ременных украшений этой эпохи с разнообразным растительным и зооморфным декором, в среде тюркоязычного населения (прежде всего воинов) и их соседей была связана с особой смысловой значимостью украшений коня и всадника. Питательной средой такой популярности можно считать мировоззренческие основы средневековой культуры кочевников, связанные с традиционными верованиями, обычаями и обрядами. Эти основы имели глубокие корни, уходящие к древнему тотемизму, культу предков и природных сил. Придание особому декору, в том числе портретным личинам, защитных, охранительных и благопожелательных функций делало его важным культурным элементом эпохи.

\section{ЛИТЕРАТУРА}

1. Алексеев В.П., Мамонова Н.Н. Палеоантропологические материалы последних веков до нашей эры и тюркского времени с территории Северо-Западного Алтая // Палеоантропология и археология Западной и Южной Сибири. Новосибирск : Наука, 1988. С. 3-21.

2. Король Г.Г. Искусство средневековых кочевников Евразии. Очерки. Москва ; Кемерово : Кузбассвузиздат, 2008. (Труды Сиб. Ассоц. исследователей первобытного искусства. Вып. V). 332 с.

3. Конькова Л.В., Король Г.Г. Опыт комплексного исследования набора средневековых ременных украшений из Саяно-Алтая // Теория и практика археологических исследований. Барнаул : Изд-во Алт. ун-та, 2007. Вып. 3. С. 89-96.

4. Мешкерис В.А. Согдийская терракота. Душанбе : Дониш, 1989. 324 с.

5. Ахмедов С.А., Джафаров Э.Б. Изображения на средневековой керамике как источник по военному делу (находки из Азербайджана) // Российская археология. 2005. № 3. С. 133-140.

6. Байпаков К.М., Терновая Г.А., Горячева В.Д. Художественный металл городища Красная Речка (VI - начало ХIII в.). Алматы : Ғылым, 2007. $304 \mathrm{c.}$

7. Байпаков К.М., Воякин Д.А., Терновая Г.А. Тенгрианство // Культурное наследие Евразии (с древности до наших дней). Алматы : Ин-т археологии им. А.Х. Маргулана, 2016. С. 121-153.

8. Король Г.Г. К вопросу о средневековой торевтике малых форм в Центральной Азии // Древности Сибири и Центральной Азии. ГорноАлтайск : Горно-Алт. гос. ун-т, 2014. № 7 (19). С. 202-215.

9. Коников Б.А. Омское Прииртышье в раннем и развитом Средневековье. Омск : Наука, 2009. 466 с.

10. Бауло А.В. Древняя бронза из этнографических комплексов и случайных сборов. Новосибирск : Изд-во ИАЭТ СО РАН, 2011.260 с.

11. Баскаков Н.А. Душа в древних верованиях тюрков Алтая (термины, их значения и этимология) // Советская этнография. 1973. № 5. С. 108-113.

12. Алексеенко Е.А. Этнокультурные аспекты изучения шаманства у кетов // Этнокультурные контакты народов Сибири. Л. : Наука, 1984. C. $50-73$.

13. Король Г.Г. «Хойцегорский портрет» рубежа I-II тыс. н.э. и манихейство в Центральной Азии // Мировоззрение населения Южной Сибири и Центральной Азии в исторической ретроспективе. Барнаул : Азбука, 2007. Вып. І. С. 81-99.

14. Мельникова Т.В. Мио, хранящее от бед // Словесница Искусств. 2004. № 2 (14). С. 10-13.

15. Дмитриева Т.Н. Изображения шаманских духов в фондах ГМИР (к вопросу о природе архаического изображения) // Образ и архетип в традициях архаики: Ритуально-мифологический контекст и семантика (Теория и методология архаики. Вып. IX). СПб. : Музей антропологии и этнографии имени Петра Великого «Кунсткамера» РАН, 2016. С. 78-93.

\section{Korol Galina G. Institute of Archaeology of RAS (Moscow, Russia).E-mail: ggkorol08@rambler.ru}

\section{REALISTIC IMAGES-"MASKS" IN MEDIEVAL CENTRAL ASIA: PORTRAIT OR SYMBOL.}

Keywords: Central Asia; the Middle Ages; toreutics of small forms; images-"masks"; semantics.

The paper aims to study the group of medieval toreutics of small forms - realistic images from the regions of Central Asa (in the broad sense of the term) as the phenomenon of art and culture of the Turkic-speaking nomads and their neighbors. The attention is paid to the place of this kind of objects in the system of spiritual and world outlook views of the owners of such ornaments. The research sources are the non-ferrous metal items (mainly belt ornaments of horses and horsemen) of the end of the 1st - beginning of the 2nd millennia $\mathrm{AD}$, which have a shape or a decor in the form of realistic images. The specificity of the topic assumes a comprehensive approach to study of the main source. Therefore, in addition to systematization, analysis of iconography, some ethnographic materials were used. Pendants shaped as human faces and face images on small toreutics pieces are concentrated in two large Central Asia regions: the Sayan and Altai Mountains (Sayan-Altai) and the Chui valley of the Tien Shan. The latter is known for the concentration of medieval hillforts. Main finds of the region are concentrated in Krasnorechenskoye. Materials from the Sayan-Altai are mainly represented by objects from burials and random finds. They are characterized as a "portrait". It allows judging not only about the image' features, yet even about their anthropological type. The latter is comparable both with paleoanthropological and modern materials (Fig. 1, 1-15, 24). For the Tien Shan materials, which have a regional identity of "portrait" images (Fig. 1, 16-19, 22, 23, 27), that have analogies from the SayanAltai, a significant peculiarity is revealed. Intimidating features been given to the realistic "portraits", that turned them into terioanthropomorphic masks (Fig. 1, 20, 21). The reasons for this require special study. The semantics of such images had a different basis than realistic ones. In both cases the anthropomorphic images had their semantics. Realistic were not just portraits, but represented generalizing images related to the world outlook and spiritual views of the regions' population. The objects that adorned the horse and horseman in the first place were always given special meaning. This is evidenced by ethnographic materials. Pictorial "plots" could have a religious content (Fig. 2). The masks of a terrifying look had a deterrent and guarding function. Realistic faces' images could contain not only a "spirit" of some person, but also a generalized type with the distinctive properties of strength, courage, etc.; but also of a tribal kind and ancestors. They were semantically endowed with the power of an entire kind according to the traditional beliefs of shamanism. They had guarding functions as well as were the conjuring of well-being (victory, life) to warriors and others. 


\section{REFERENCES}

1. Alekseev, V.P. \& Mamonova, N.N. (1988) Paleoantropologicheskie materialy poslednikh vekov do nashey ery i tyurkskogo vremeni s territorii Severo-Zapadnogo Altaya [Paleoanthropological materials of the last centuries BC and Turkic time from the territory of the North-West Altai]. In: Alekseev, V.P. (ed.) Paleoantropologiya i arkheologiya Zapadnoy i Yuzhnoy Sibiri [Paleoanthropology and Archeology of Western and Southern Siberia]. Novosibirsk: Nauka. C. 3-21.

2. Korol, G.G. (2008) Iskusstvo srednevekovykh kochevnikov Evrazii. Ocherki [The Art of Medieval Eurasian Nomads]. Moscow; Kemerovo: Kuzbassvuzizdat.

3. Konkova, L.V. \& Korol, G.G. (2007) Opyt kompleksnogo issledovaniya nabora srednevekovykh remennykh ukrasheniy iz Sayano-Altaya [A complex study of a set of medieval belt ornaments from the Sayano-Altai]. In: Tishkin, A.A. (ed.) Teoriya i praktika arkheologicheskikh issledovaniy [Theory and Practice of Archaeological Research]. Issue 3. Barnaul: Altai State University. pp. 89-96.

4. Meshkeris, V.A. (1989) Sogdiyskaya terrakota [Sogdian terracotta]. Dushanbe: Donish.

5. Akhmedov, S.A. \& Dzhafarov, E.B. (2005) Izobrazheniya na srednevekovoy keramike kak istochnik po voennomu delu (nakhodki iz Azerbaydzhana) [Images on medieval ceramics as a source on military affairs (finds from Azerbaijan)]. Rossiyskaya arkheologiya - Russian Archeology. 3. pp. 133140.

6. Baypakov, K.M., Ternovaya, G.A. \& Goryacheva, V.D. (2007) Khudozhestvennyy metall gorodishcha Krasnaya Rechka (VI - nachalo XIII v.) [Metal Art of the Krasnaya Rechka Ancient Settlement (the 6th - early 13th centuries)]. Almaty: Fylym.

7. Baypakov, K.M., Voyakin, D.A. \& Ternovaya, G.A. (2016) Tengrianstvo [Tengrianism]. In: Khaidarov, T.F. et al. Kul'turnoe nasledie Evrazii (s drevnosti do nashikh dney) [Cultural Heritage of Eurasia (From Ancient Times To the Present)]. Almaty: A.Kh. Margulan Institute of Archeology. pp. 121-153.

8. Korol, G.G. (2014) K voprosu o srednevekovoy torevtike malykh form v Tsentral'noy Azii [On medieval toreutics of small forms in Central Asia]. Drevnosti Sibiri i Tsentral'noy Azii. 7(19). pp. 202-215.

9. Konikov, B.A. (2007) Omskoe Priirtysh'e v rannem i razvitom Srednevekov'e [Omsk Priirtyshye in the Early and Developed Middle Ages]. Omsk: Nauka.

10. Baulo, A.V. (2011) Drevnyaya bronza iz etnograficheskikh kompleksov i sluchaynykh sborov [Ancient Bronze from Ethnographic Complexes and Random Collections]. Novosibirsk: SB RAS.

11. Baskakov, N.A. (1973) Dusha v drevnikh verovaniyakh tyurkov Altaya (terminy, ikh znacheniya i etimologiya) [Soul in the ancient beliefs of the Altai Turks (terms, their meanings and etymology)]. Sovetskaya etnografiya. 5. pp. 108-113.

12. Alekseenko, E.A. (1984) Etnokul'turnye aspekty izucheniya shamanstva u ketov [Ethno-cultural aspects of studying shamanism in the Kets]. In: Taksami, Ch.M. (ed.) Etnokul'turnye kontakty narodov Sibiri [Ethnocultural Contacts of Siberiam People]. Leningrad: Nauka. pp. 50-73.

13. Korol, G.G. (2007) "Khoytsegorskiy portret" rubezha I-II tys. n.e. i manikheystvo v Tsentral'noy Azii [The "Khoytsegorsky portrait" of the boundary of the 1st-2nd centuries AD and Manichaeism in Central Asia]. In: Dashkovaksiy, P.K. (ed.) Mirovozzrenie naseleniya Yuzhnoy Sibiri i Tsentral'noy Azii $v$ istoricheskoy retrospective [Worldviews of the population in Southern Siberia and Central Asia in historical retrospect]. Issue 7. Barnaul: Azbuka. pp. 81-99.

14. Melnikova, T.V. (2004) Mio, khranyashchee ot bed [Mio, keeping from misfortunes]. Slovesnitsa Iskusstv. 2(14). pp. 10-13.

15. Dmitrieva, T.N. (2016) Izobrazheniya shamanskikh dukhov v fondakh GMIR (k voprosu o prirode arkhaicheskogo izobrazheniya) [Images of shamanic spirits in the funds of the State Museum of Religion History (to the question of the nature of the archaic image)]. In: Albedil, M.F. \& Savinov, D.G. (eds) Obraz $i$ arkhetip v traditsiyakh arkhaiki: Ritual'no-mifologicheskiy kontekst $i$ semantika [Image and Archetype in the Archaic Traditions: Ritual and Mythological Context and Semantics]. St. Petersburg: Museum of Anthropology and Ethnography. pp. 78-93. 